\title{
THE EFFECT OF DIFFERENT POST MATERIALS AND CEMENTS ON FRACTURE RESISTANCE OF ENDODONTICALLY TREATED TEETH -AN IN VITRO STUDY
}

\author{
Rajneesh Kumar ${ }^{1}$, Nisha Garg ${ }^{2}$, Poonam Bogra ${ }^{3}$, Vineeta Nikhil ${ }^{4}$, Amit Garg ${ }^{5}$, Anamika Thakur ${ }^{6}$ \\ ${ }^{1}$ Professor, Dept. of Conservative Dentistry and Endodontics, Sri Sukhmani Dental College and Hospital, Punjab, India \\ ${ }^{2}$ Professor, Dept. of Conservative Dentistry and Endodontics, Bhojia Dental College and Hospital, Himachal Pradesh, India \\ ${ }^{3}$ Professor, Dept. of Conservative Dentistry and Endodontics, D.A.V Dental college and Hospital, Haryana, India \\ ${ }^{4}$ Professor, Dept. of Conservative Dentistry and Endodontics, Subharti dental College, Uttar Pradesh, India \\ ${ }^{5}$ Reader, Dept. of Oral and Maxillofacial Surgery, Sri Sukhmani Dental College and Hospital, Punjab, India \\ ${ }^{6}$ Sr. Lecturer, Dept. of Conservative Dentistry and Endodontics, Sri Sukhmani Dental College and Hospital, Punjab, India
}

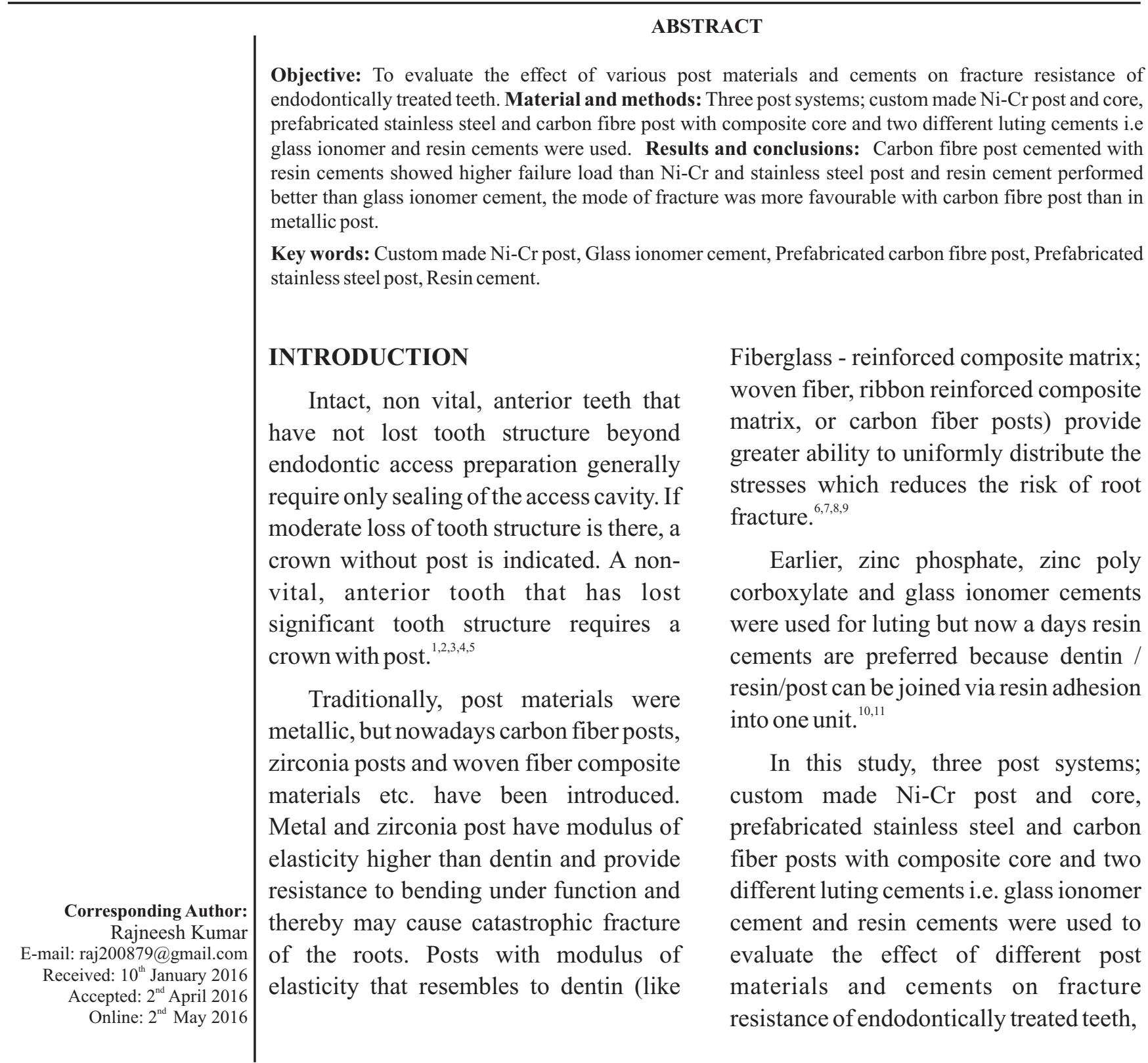




\section{MATERIALS AND METHODS}

35 intact, caries free, maxillary central incisors of patients aged 45-55 were obtained. Teeth were stored in normal saline at room temperature till the study was conducted. Root canals were prepared by the use of Kfiles (Mani Inc, Tochigi - Ken, Japan), enlarged to no. 45 files using step back technique and the prepared canals were obturated with laterally condensed guttapercha points using AH-26 as sealer. After root canal preparation teeth were randomly divided into 4 groups, 3 groups of 10 specimens each and 1 control group of 5 specimens. The groups I, II \& III were further subdivided into 2 subgroups of 5 specimens each. Specimens of groups I, II and III were sectioned $3 \mathrm{~mm}$ above CEJ ${ }^{5}$ and a shoulder finish line of $1 \mathrm{~mm}$ was created at this level around full circumference of teeth. Post space was prepared using a drill of $1.5 \mathrm{~mm}$ diameter up to a depth of $10 \mathrm{~mm}$ under full water irrigation (Figure 1, Figure 2 and Figure 3).

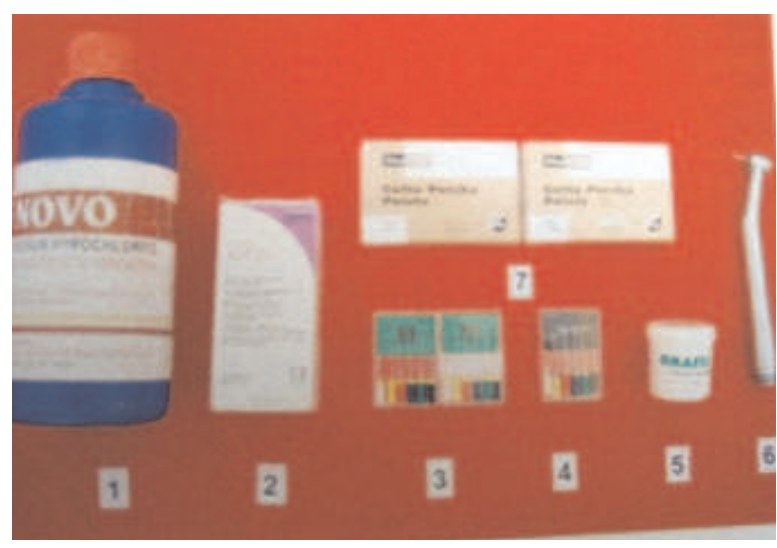

Figure 1

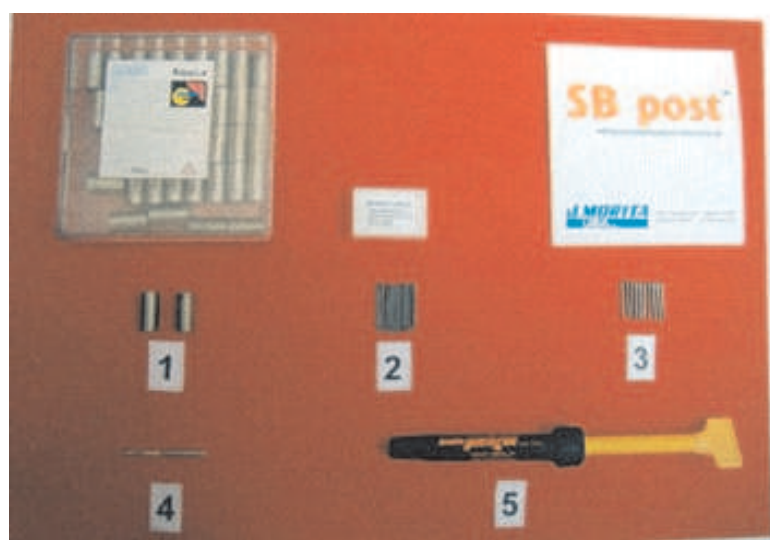

Figure 2

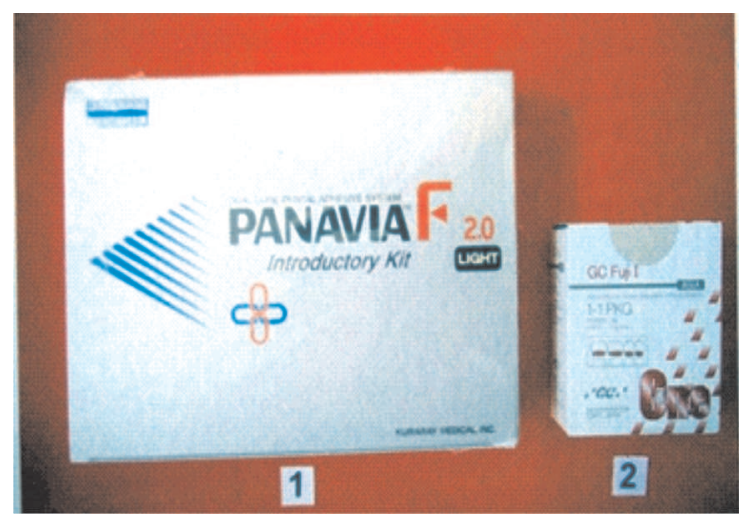

Figure 3

Group I teeth were restored with Ni-Cr post and core, Group II with stainless steel post and composite core, Group III with Carbon fibre post and composite core. Group I, II, III were further subdivided in to subgroups "a" and "b" having 5 specimen of each. In subgroup "a" posts were cemented with Glass ionomer cement whereas in subgroup "b" posts were cemented with resin cement. Group IV (Control) teeth were restored with crown preparations without post and core. Crown preparation was done according to the standardized technique with a uniform $1.0 \mathrm{~mm}$ reduction. Incisor to CEJ dimension was $6-7 \mathrm{~mm}$ in all preparations. Crowns were fabricated on the teeth using Nidaur Ni$\mathrm{Cr}$ alloy, then sandblasted and cleaned with steam under pressure. Resin cement was used to cement these crowns (Figure 4).

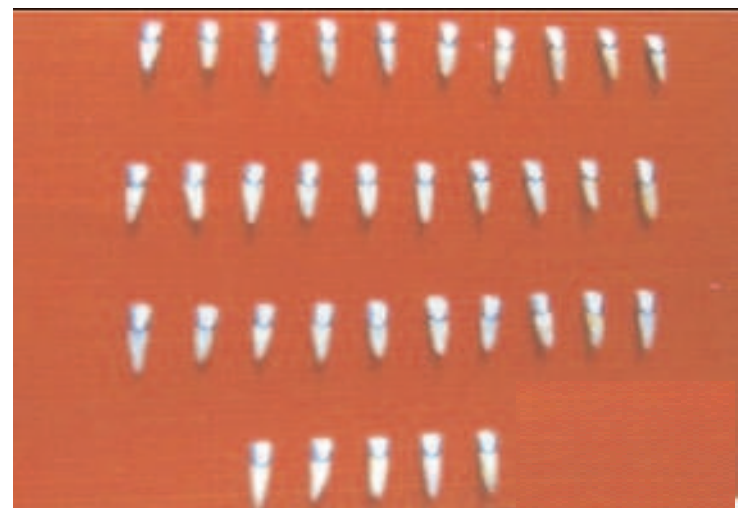

Figure 4

Root surfaces were marked $2 \mathrm{~mm}$ below the CEJ and covered with two $0.1 \mathrm{~mm}$ foils. Specimens were then embedded in autopolymerizing acrylic resin surrounded by aluminium cylinders (Figure 5). After 
first sign of polymerization, teeth were extracted from resin blocks and spacers were removed from the root surfaces (Fig 5). Silicon base impression material was injected into acrylic resin moulds (Figure 5), and teeth were reinserted into resin cylinders (Figure 5). Standardized silicon layers that simulated periodontal ligament were thus created. Specimens were mounted in retaining arm of Universal Testing Machine 'INSTRON' (Figure 6). The load was applied at a $130^{\circ}$ angle to the long axis by use of a steel rod with rounded end. Point of load application was middle of the lingual surface. Cross-head speed was $50 \mathrm{~mm} / \mathrm{min}$, and the specimens were loaded to fracture with load values measured in Kgs. Fracture mode was also recorded.

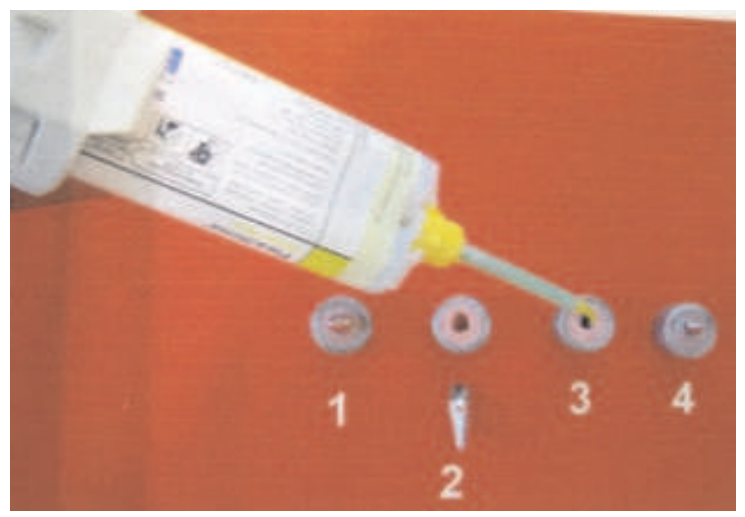

Figure 5

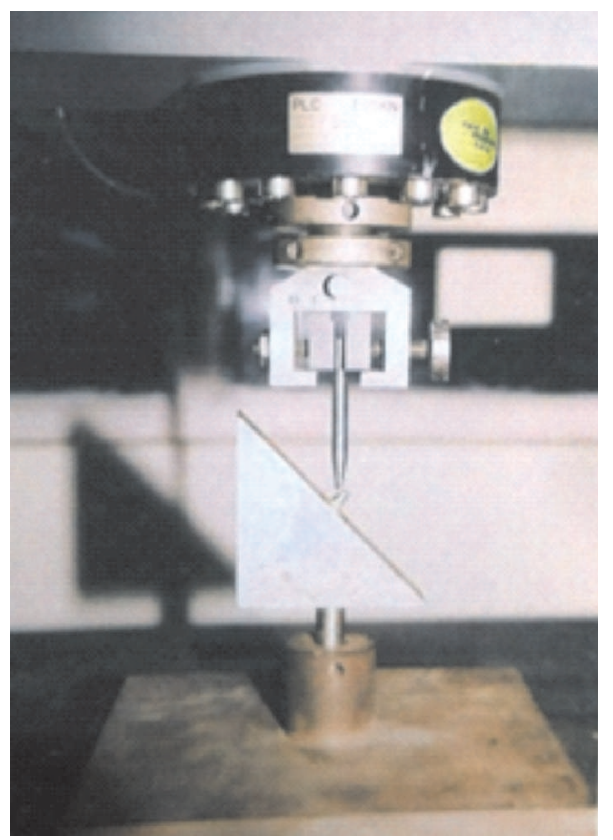

Figure 6

\section{RESULTS}

Comparison of mean values of all the groups is illustrated graphically in Graph 1. Mean and standard deviation of the obtained values for each group are presented in Table 1.

One way analysis of variance showed significant difference $(\mathrm{F}=9.45678, \mathrm{p}<0.0001)$ between the groups (Table 2). Unpaired student ' $t$ ' test was than conducted to establish which of the groups were significantly different from one another.

When Group Ia was compared with other groups using student ' $t$ ' test there was a statistically significant difference $(\mathrm{p}<0.05)$ between Group Ia and Ib, IIb, IIIa, IIIb, and IV. There was statistically insignificant difference $(p>0.05)$ between Group Ia and IIa $(\mathrm{p}=0.85859)$.

When Group Ib was compared with other groups using student ' $t$ ' test there was a statistically significant

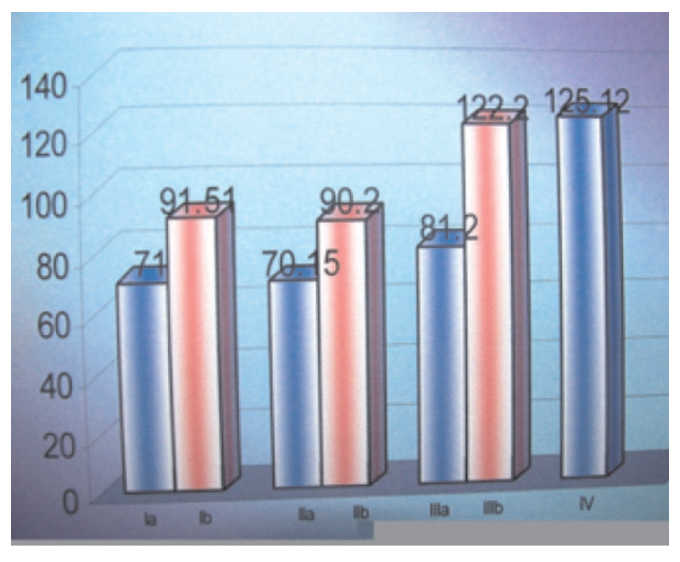

Graph 1: Comparison of mean load failure of different groups (load in kgs)

Table 1: Mean and Standard Deviation table

\begin{tabular}{|l|l|l|l|}
\hline Group & No. of samples & $\begin{array}{l}\text { Mean Load } \\
\text { Failure (Kgf) }\end{array}$ & $\begin{array}{l}\text { Standard } \\
\text { deviation }\end{array}$ \\
\hline Ia & 5 & 71.00 & 6.0000 \\
\hline Ib & 5 & 91.51 & 12.1175 \\
\hline IIa & 5 & 70.15 & 8.4719 \\
\hline IIb & 5 & 90.20 & 10.1737 \\
\hline IIIa & 5 & 81.20 & 4.3397 \\
\hline IIIb & 5 & 122.20 & 10.2235 \\
\hline IV & 5 & 125.12 & 6.5793 \\
\hline
\end{tabular}


Table 2: Analysis of variance (ANOVA) for failure load of various groups.

\begin{tabular}{|l|c|l|l|l|}
\hline $\begin{array}{l}\text { Source of } \\
\text { Variation }\end{array}$ & $\begin{array}{l}\text { Degree of } \\
\text { freedom }\end{array}$ & $\begin{array}{l}\text { Variance } \\
\text { ratio }\end{array}$ & 'p' value & Inference \\
\hline Between group & 3 & 9.45678 & 0.00014 & $\begin{array}{l}\text { Highly } \\
\text { significant }\end{array}$ \\
\hline Within Group & 31 & & & \\
\hline Total & 34 & & & \\
\hline
\end{tabular}

difference between Group Ib and Ia, IIa, IIIb and IV and statistically insignificant difference $(p>0.05)$ between group $\mathrm{Ib}$ and $\mathrm{IIb}(\mathrm{p}=0.33182)$. Fracture mode of each group is illustrated graphically in graph 2 . Results of fracture modes of each group were analysed with non parametric Chi - Square $\left(\chi^{2}\right)$ test. Test revealed that there were significant differences in fracture mode among the 4 groups. Value of Chi Square with 12DF is $29.8308, \mathrm{p}<0.002961$.

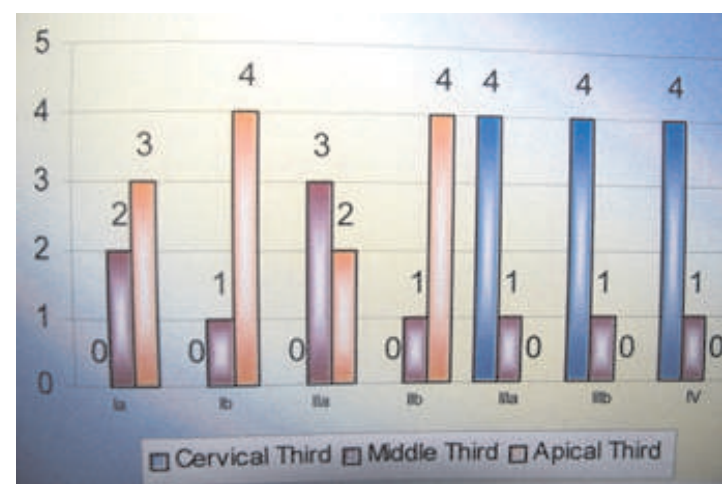

Graph 2: Mode of fracture of various groups

\section{DISCUSSION}

Present study involved in vitro comparison of effect of three different post and core materials and two different luting cements on the fracture resistance of endodontically treated teeth. When teeth restored with custom made $\mathrm{Ni}-\mathrm{Cr}$ post and core cemented with glass ionomer cement (Ia) were compared with teeth restored with $\mathrm{Ni}-\mathrm{Cr}$ post and core cemented with resin cement (Ib), the mean load failure of group Ib $(91.51 \mathrm{kgs})$ was higher than that of group Ia $(71.00 \mathrm{kgs})$ and the results were statistically significant $(\mathrm{p}<0.05)$. The results obtained in the present study are in agreement with
Mendoza DB et al (1997) ${ }^{12}$ who evaluated resin bonded preformed metal posts cemented with resin cement and zinc phosphate cement. He showed significantly more resistance to fracture with resin cement than with zinc phosphate. Higher failure load for group $\mathrm{Ib}$ can be explained by the fact resin cement has modulus of elasticity (16 GPa) which is almost comparable to dentin (18.3GPa). Thus, resin cement absorbs part of the load applied to the root, reducing the risk of root fracture. Similar results were seen when stainless steel posts cemented with glass ionomer cement (IIa) were compared with teeth restored with prefabricated stainless steel posts cemented with resin cement (IIb), and $\mathrm{Ni}-\mathrm{Cr}$ posts cemented with glass ionomer cement (Ia) were compared with teeth restored with prefabricated stainless steel posts cemented with resin cement (IIb). When the teeth restored with prefabricated carbon fiber posts cemented with glass ionomer cement (IIIa) were compared with teeth restored with prefabricated carbon fiber posts cemented with resin cement (IIIb), the mean failure load for group IIIb (122.20kgs) was higher than group IIIa $(81.20 \mathrm{kgs})$ and the results were statistically significant $(p<0.05)$. Because resin cement showed bonding to both dentin and carbon fiber posts giving a single unit effect and causing uniform stress distribution but glass ionomer cement showed chemical bonding only to dentin. When the teeth restored with custom made $\mathrm{Ni}-\mathrm{Cr}$ posts cemented with glass ionomer cement (Ia) were compared with teeth restored with prefabricated carbon fiber posts cemented with glass ionomer cement (IIIa), the mean failure load for group IIIa $(81.20 \mathrm{kgs})$ was higher than group Ia $(71.00 \mathrm{kgs})$ and the results were statistically significant $(p<0.05)$. Results of present study are in agreement with Isidor $F$ et al (1996) ${ }^{13}$ who found that when intermittent loading of 2 cycles/sec., with a peak load of $250 \mathrm{~N}$ perpendicular to occlusal surface of crown was applied, carbon fiber posts had not failed 
even after 1,000,000 loads where as teeth with custom cast posts or titanium posts failed before 260,000 cycles. Ottl et al (2002) ${ }^{14}$ found that carbon fiber posts had highest failure loads followed by metal posts and ceramic posts. Similarly Dean JP et al (1998) ${ }^{15}$ found the same about carbon fiber posts. Higher failure load for group IIIa can be explained by the fact that modulus of elasticity of carbon fiber posts (15GPa) was almost similar to that of dentin $(18.3 \mathrm{GPa})$ resulting in distribution of stresses along whole of the root dentin. Modulus of elasticity of Ni-Cr alloy (171.7GPa) was much higher than that of dentin resulting in concentration of stresses causing the teeth to fracture.

Results obtained in present study are contrary to those obtained by $\mathrm{Hu}$ YH et al (2003) ${ }^{16}$ and Raygot et al $(2001)^{17}$, who found no difference in fracture load for carbon fiber posts and metal posts. Sidoli GE (1997) ${ }^{18}$ found that higher failure load was seen in cast metal posts and other metal posts and carbon fiber posts showed lowest mean values for failure load.

Mean failure load for group IIIa $(81.20 \mathrm{kgs})$ was higher than group IIa $(70.15 \mathrm{kgs})$ and results were statistically significant $(p<0.05)$. Higher failure load for group IIIa can be explained as above for group Ia and IIIa.

Mean failure load for group IIIb (122.20kgs) was higher than group $\mathrm{Ib}(91.51 \mathrm{kgs})$ and the results were statistically significant $(p<0.05)$. The higher failure load for group IIIb can be explained by the fact that when teeth were restored with carbon fiber posts and resin cement they behaved as one unit and thereby resulted in uniform stress distribution causing reinforcing effect on the tooth and effect of the posts can be explained as above for group Ia and IIIa. Similar results were seen when we compared group IIIb with Ia and IIIb with IIa.

When the teeth with only a crown and no post and core (Group IV) were compared with Groups Ia, Ib, IIa,
IIb and IIIa the mean failure load for Group IV $(125.12 \mathrm{~kg})$ was higher than mean failure load of Group Ia (71.00kgs), Ib (91.51 kgs), IIa (70.15kgs), IIb $(90.20 \mathrm{kgs})$ and IIIa $(81.20 \mathrm{kgs})$ and results obtained were statistically significant. This showed that natural tooth with endodontic treatment performed better than all these groups. Guzy GE found the same in his study. ${ }^{19}$

When teeth restored with prefabricated carbon fiber posts cemented with resin cement (IIIb) was compared with control group (IV), the mean failure load for Group IIIb (122.2kgs) was almost similar to that for Group IV (125.12kgs) and results so obtained were statistically insignificant $(p>0.05)$. This can be explained by the fact that carbon fiber post and resin cement when used, act as one unit and behaved like a natural tooth.

Mode of failure of different groups revealed that unfavorable (middle and coronal third) root fractures were seen in teeth restored with $\mathrm{Ni}-\mathrm{Cr}$ and stainless steel posts, and favorable root fractures with carbon fiber posts. In teeth restored with carbon fiber posts uniform distribution of stresses occurs whereas concentration of stresses occurs with metallic posts which may lead to fracture of root. ${ }^{20,21,22}$

\section{CONCLUSION}

- Resin cement performed better than glass ionomer cement irrespective of post material used.

- Carbon fiber posts showed higher failure load than custom made $\mathrm{Ni}-\mathrm{Cr}$ posts and prefabricated stainless steel posts.

- Carbon fiber posts cemented with resin cement performed almost equal to the endodontically treated teeth with no post and core.

- Mode of fracture was more favourable with carbon fiber posts group than in metallic posts.

\section{REFERENCES}

1. Cohen Burns. Pathways of the Pulp: $8^{\text {th }}$ Ed.; Mosby Pb. 2002.

2. Ingle, Bakland. Endodontics: $5^{\text {th }}$ Ed.; William \& Wilkins $\mathrm{Pb} .2002$. 
3. Marzouk, Simonton AL., Gross RD. Operative DentistryModern Theory and practice. Ist Ed.; Ishiyaku Euro. American Inc. 1997.

4. Rosensteil. Contemporary Fixed Prosthodontics 2nd Ed. Mosby Pb. 1995.

5. Weine . Endodontic therapy: $6^{\text {th }}$ Ed.; Mosby Pb. 2004.

6. Akkayan B, Gulmez T. Resistance to fracture of endodontically treated teeth restored with different post systems. J Prosthet Dent 2002; 87: 431 - 437.

7. Al-harbi F, Nathanson D. In vitro assessment of retention of four esthetic dowels to resin core foundation and teeth. J Prosthet Dent 2003; 90: 547 - 555.

8. Asmussen E, Peutzfeldt A, Heitmann T. Stiffness, elastic limit and strength of newer types of endodontic posts. J Dent 1999; 27: $275-278$.

9. Butz F. Survival rate and fracture strength of Endodontically treated maxillary incisors with moderate defects restored with different post and core system; An invitro study. Int $\mathrm{J}$ Prosthodont. 2001; 14: 58-64.

10. Mezzomo E, Massa F, Libera SD. Fracture resistance of teeth restored with two different post and core designs cemented with two different cements: An in vitro study. Part I. Quintessence Int. 2003; 34: 301 - 306.

11. Raygot CG, Chai J, Jameson DL. Fracture resistance and primary failure mode of endodotnically treated teeth restored with a carbon fiber - reinforced resin post system in vitro. Int $\mathrm{J}$ Prosthodont 2001; 14: 141 - 145.

12. Mendoza DB. Root reinforcement with a resin bonded preformed post. J Prosthet Dent. 1997; 78: 10 - 15.
13. Isidor $\mathrm{F}$, Odman $\mathrm{P}$, Brondum $\mathrm{K}$. Intermittent loading of teeth using prefabricated carbon fiber posts. Int J Prosthodont. 1996; 9: $131-136$.

14. Ottl P. Fracture characteristics of carbon fiber, ceramic and non-palladium endodontic post systems as monotonously increasing loads. J Oral Rehabil 2002; 29: 175 - 183.

15. Dean JP, Jeansonne BG, Sarkar N. In vitro evaluation of a carbon fiber post. JEndod 1998; 24 (12): 807 - 810.

16. $\mathrm{Hu} \mathrm{Y}-\mathrm{H}$. Fracture resistance of endodontically treated anterior teeth restored with four post and core systems. Quintessence Int 2003; $34: 349$ - 353 .

17. Raygot CG, Chai J, Jameson DL. Fracture resistance and primary failure mode of endodotnically treated teeth restored with a carbon fiber - reinforced resin post system in vitro. Int J Prosthodont 2001; 14: 141 - 145.

18. Sidoli G E .: An invitro evaluation of a carbon fiber based post and core system. J Prosthet Dent. 1997; 78: 5 -9.

19. Guzy GE, Nicholls JI. Invitro comparison of intact endodontically treated teeth with and without endo-post reinforcement. Part-I. J Prosthet Dent 1979; $42: 39$ - 44.

20. Bergman B, Lundquist $P$ et al. Restorative and endodontic results after treatment with cast posts and cores. J Prosthet Dent. 1989, 61: 10 - 15 .

21. Condos S, Deutsch AS, Musikant BL. Fracture strength of three different core materials in combination with there different endodotnic posts. Int J Prosthodont. 1994; 7 : 178 182.

22. Dale JW. A clinical evaluation of semi-precious alloys for dowels and cores. J Prosthet Dent. 1977; 38: 161 - 167. 